\title{
DENTAL FLUOROSIS
}

\author{
BY \\ H. SAINSBURY \\ (Late Captain, R.A.M.C.)
}

The following account is given to demonstrate how dental fluorosis in a particular locality presents itself to the casual observer. The teeth of a boy first attracted attention on account of their dark brown discolouration. The staining resembled that of nicotine, but on closer examination proved to be too dark to be attributable to smoking in a boy, whilst the boy's fingers were not stained. On enquiry, the local inhabitants attributed the condition to 'iron' in the water, remarking that teeth in the district were bad: they tended to chip and rot early.

Opportunity shortly afterwards presented itself to examine some 150 children, representing between a third and a half of the whole school population, when special attention was paid to the condition of their teeth. The writer had not previously met with some of the lesions presented, but a description of the condition in a recent issue of the British Medical Journal suggested that they were those of fluorosis. Standard medical textbooks which were to hand contained no reference to the condition. Accordingly sketches (reproduced below) were made at the time, and have since been confirmed from the descriptions of McKay (1916) and subsequent writers. The age distribution of the lesions is shown below (fig. 1).

The lesions took the following forms:

1. Hypoplasia of Dental enamel. (a) The enamel was extremely thin but smooth. and in places deficient. leaving small circular bared areas of dentine varying from 1 to $\frac{1}{4} \mathrm{~mm}$. in diameter. The larger ones might have been punched out with an ophthalmic trephine-if that were possible-so clean cut and regular were the edges. This lesion occurred unaccompanied by any other.

(b) Pitting: Small pits with sloping edges were scattered over the outer surface of the front teeth. Often they were seen as a single or double horizontal row. The biting edge of the other teeth tended to be ragged but the central incisors had a worn straight cutting edge. This appearance was recognized as significant of rickets and acute infections during the first year of life, which conditions were extremely prevalent in this locality. Thus the lesion on account of its mixed etiology had to be disregarded. A third but rare condition giving a similar appearance is that of partial agenesis of enamel (Sprawson, 1942).

2. Decalcified aReas. These were irregular patches of opaque white enamel. Clearly circumscribed patches occurred with mottling and pitting. But in other cases the patches covered the surface of the tooth and their edges were diffuse. They showed up as a dull white in contrast to the translucency of normal enamel. Disorders of calcium metabolism during early infancy frequently give rise to the former appearance, but the latter is more typical of fluorine intoxication.

3. MotTling. The enamel was unequal in thickness, forming ridges which were frequently arranged horizontally. This again is not typical of fluorosis but of any condition which interferes with the development of the enamel organ.

4. 'BROWNIN' or patches of brown stain, which reached a depth of chocolate in colour, appeared superficial and were confined to the outer surface of the upper front teeth below the lip line. This is the

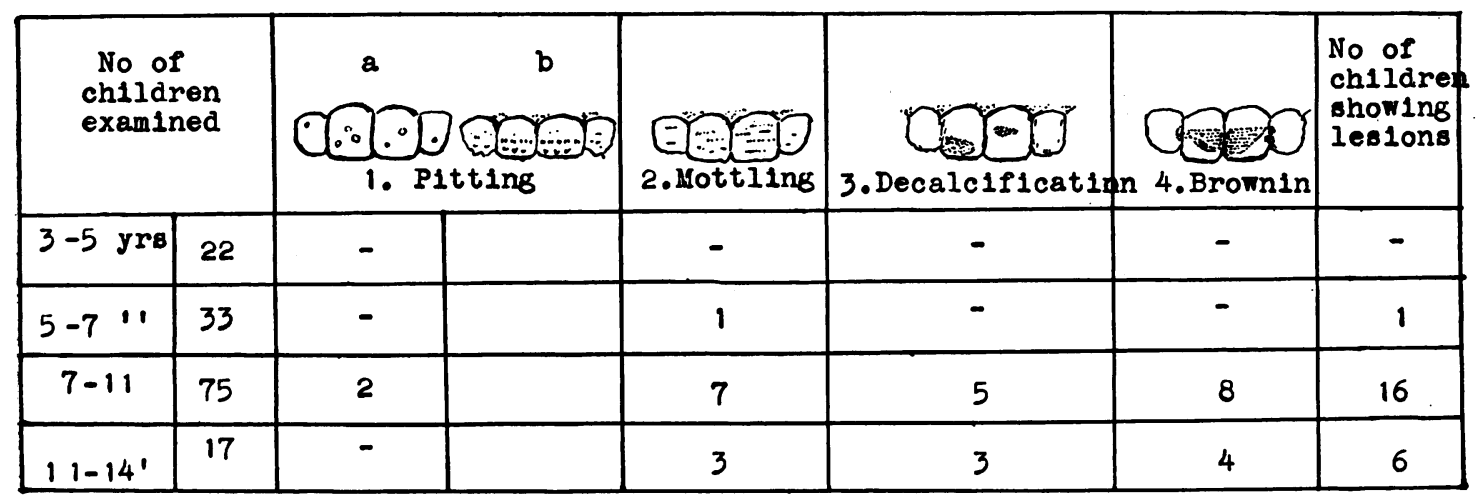

FIG. 1.-Showing the Age Distribution of the various types of lesion noted. 
typical lesion of fluorosis and when fully developed is diagnostic. Congenital syphilis can produce a muddiness, which might simulate mild cases. Hereditary opalescent dentine is apparently similar in appearance but affects all the teeth (Sprawson, 1942). Both conditions are, however, rare.

Other Characteristics of the Group. There was a tendency for the condition to occur more frequently among those children who showed evidence of previous rickets. The figures were small and not conclusive. Pillai, Rajogopalan. and De (1944) showed that in rats it is possible to suppress the lesions with an increased calcium intake.

Of the whole sample only four children showed any evidence of dental caries. This was scarcely surprising since these were a primitive people living largely on a vegetable diet, and as Crighton-Brown (1892) pointed out the fluorides contained in coarse milled flour limit caries.

Filling out of the lumbar curve was observed in two children, both showing some malnutrition but neither dental lesions. In England Kemp (1942) was unable to find any definite X-ray evidence in children of the osteo-arthritis and spondylitis noted by Miller and Roholm among adult cryolite workers.

Endemic goitre was conspicuous in the locality. It has been pointed out by Wilson (1941) that the two conditions tend to coexist. An iodine estimation of the water, however, was not possible.

The Locality. The area in question was a small village, 'Lauro', situated on the edge of the Naples plain, some twenty-five miles from that city. It was in this region that fluorosis, originally known as 'Denti Neri' on account of the stain, was first recognized by the Italian physician Stephano Chiaie and later by Eager (1901).

The village is some twenty miles from Mount Vesuvius and the whole area volcanic. Roholm (1937) summarizes the results of six geological surveys done in the plain between 1910 and 1926 . Fluorine was found in the following forms: HF, $\mathrm{K}_{2} \mathrm{SiF}$, and $\mathrm{KBrF}$, which differ from those found in England, where the important compound is Fluorapatite $\left(3 \mathrm{P}_{2} \mathrm{O}_{8} \mathrm{Ca}_{3}, \mathrm{CaF}\right)$, and from those in Greenland, where it is Cryolite $\left(\mathrm{Na}_{3} \mathrm{AlF}_{6}\right)$. Samples of rock were examined spectroscopically but the typical bands shown by Churchill (1931) were not seen. Another specimen was sent to the Geological Survey, London, for miscroscopical examination and described as Creataceous Limestone. Mr. C. N. Bromehead commented that the fluorine mineral is volcanic ash, which should have been found on this limestone; and is, in fact, dusted over the ridge of a hill, which overlooks the village and which forms the gathering ground of the local water supply. This ash is said to contain from 0.25 per cent. to 0.96 per cent. fluorine.

The Water. The water is derived from four deep wells. It is not treated in any way. Routine chemical analysis revealed no abnormality. The fluorine content was estimated by the Barr and
Thorogood colorimetric method (Suckling, 1942) and found to be 7 parts per million. It is generally agreed that lesions occur where the concentration rises above 1 part per million, and Dean (1934) holds that such a figure would be accompanied by well marked lesions. Samples should be collected in containers of glass free from soluble fluorides.

Apart from changing the water supply as a preventative measure, it is possible to treat the water with calcium phosphate, manganese oxide, or aluminium phosphate.

Pathology. Fluorides are found in breast milk and can be recovered from the urine. Affected teeth and bones show an increase in their fluorine content. Enamel changes alone are to be found in childhood and are associated with delayed dentition. The enamel lesions appear to be due to the toxic effect of fluorine upon the ameloblasts of the enamel organ, causing their destruction and changes in their arrangement, together with subsequent imperfect calcium precipitation in the preprismatic fibres. At the same time the interstitial tissue is defective, making the teeth friable and causing bundles of prisms to be shed with the formation of pits. The brown stain is probably due to the deposition of food constituents between the prisms.

Symptoms. Apart from the unsightly appearance of the teeth, there are no symptoms in childhood. The early destruction of the teeth and crippling rheumatic symptoms arising out of bony changes, which occur later in adult life, however, make this condition one of some importance.

Local treatment is directed to improving the appearance of the teeth (where the stain is slight) with 12 per cent. $\mathrm{HCl}$ or filing the enamel surface. Usually, however, the teeth have ultimately to be extracted. Maintenance of the nutrition of the child is of particular importance.

\section{Summary}

The main features of a series of cases of dental fluorosis are described as they were presented among the children of a small village. The more important points which emerge are:

1. The appearance of 'brownin' is the most striking and certain indication of the presence of the condition. It was this appearance which attracted the attention of Ainsworth (1933) in England.

2. 'Brownin' closely resembles tobacco staining, but among children, where it develops slowly, the pigment is confined to the outer surface of the upper teeth.

3. Of the lesions noted (pitting, mottling, chalk patches and 'brownin') only the latter can be produced by fluorosis alone. Differential diagnosis is given in the case of the other lesions and it is to be noted that the coexistence of acute infections and nutritional defects in infancy render the precise 
estimation of the amount of fluorosis prevailing in a locality difficult.

4. The lesions occur on the permanent teeth only.

$\cdot 5$. No evidence of osteo-arthritis was observed among the children.

6. The incidence of dental caries was low ( $2 \cdot 7$ per cent.).

7. Endemic goitre was present in the district.

8. Clinical findings were confirmed by finding fluorine present to the extent of 7 parts per million in the water.

Acknowledgment is made to Mr. C. N. Bromehead of the Geological Survey and Museum, London; to Dr. A. Stewart of the Royal Institute of Public Health and Hygiene, London; and to Dr. Margaret Murray of Bedford College, London, for information and help with the investigations.

\section{REFERENCES}

Ainsworth, N. J. (1933). Brit. dent. J., 55, 233.

Churchill, H. V. (1931). Ind. and Eng. Chem., 23, 996.

Crighton-Brown (1892). Lancet, 2, 6.

Dean, H. V. (1934). J. Amer. dent. Ass., 21, 1921.

Eager, J. M. (1901). U.S. Public Health Report, 16, 2576.

Kemp, F. H., Murray, M. and Wilson, D. C. (1942). Lancet, $2,92$.

McKay, F. S., Black, G. V. (1916). Dental Cosmos, 58, 129.

Pillai, Rajogopalan, and De (1944). R. Ind. med. Gaz., $79,248,261$.

Roholm, K. (1937). Fluorine Intoxication, London.

Sprawson, E. and Collier (1942). Dental Anatomy and Pathology Ed. 8. London.

Suckling, E. V. (1943). The Examination of Waters and Water Supplies, Ed. 5, London, 317.

Wilson, D. C. (1941). Lancet, 1, 211. 